\title{
Study of Emergency Power Based on Solar Battery Charging
}

\author{
Lei Wang, Mengfu Zhu ${ }^{a}$, Ping Chen, Cheng Deng, Zhimeng Liu, Yanan Wang \\ Institute of Medical Equipment, Academy of Military Medical Sciences, Tianjin 300161, China
}

\begin{abstract}
To study an emergency power based on solar battery charging. Based on the electric-generation principle of solar panel, solar energy is changed into electrical energy. Through voltage conversion circuit and filter circuit, electrical energy is stored in the energy storage battery. The emergency power realizes the conversion from solar energy to electrical energy. The battery control unit has the function of PWM (Pulse-Width Modulation) charging, overcharging protection, over-discharging protection and over-current protection. It also realizes the fast and safe charging of energy storage battery. The emergency power could provide both $12 \mathrm{~V}$ AC power for emergency equipment such as miniature PSA oxygen concentrator and 5V USB for electronic equipment (mobile phone, GPS device, rechargeable light, etc.).
\end{abstract}

Keyword. Solar; emergency power; MCU; energy storage battery

\section{Introduction}

When natural disaster and accident occur, scores of injured people need treatment and care. Taking in oxygen without delay can reduce the rate of injury and death[1, 2]. With the characteristics of light weight, small size and easy carrying, miniature PSA oxygen concentrator is an important and effective oxygen device for the sick and wounded[3]. However, if the power station equipment are damaged or the power supply goes bad, it is usually unable for the miniature PSA oxygen concentrator to work properly, which severely affects the efficiency of rescuing the sick and wounded. Besides, when hikers are unable to get a fixed power in the wild or in remote areas, electronic device, such as mobile phone, GPS device, and rechargeable light, can't be normal used for long time, which usually affects the quality of people's lives, even triggers survival crisis. As a new clean, green and renewable energy resource, solar energy, is gathering increasingly attention. Solar power system can charge and store electricity by absorbing the solar energy. It is chiefly discussed in this paper that based on the principle of solar battery charging, study an emergency power, providing $5 \mathrm{~V}$ USB power for miniature PSA oxygen concentrator and $12 \mathrm{~V}$ DC power for electronic device without external power support, to improve people's quality of life or survival[4-6].

\section{Scheme Design}

The emergency power based on solar battery charging (hereafter referred to as emergency power) is mainly composed of solar panel, battery control unit, and energy storage battery. The overall frame of the emergency power is shown in Figure 1. The solar panel converts the solar energy into electrical energy with suitable charging voltage after DC-DC conversion circuit and filter circuit, in the meantime, the battery control unit realizes the over-charging protection and over-current protection of power supply circuit by monitoring terminal voltage and load current of the energy storage battery, which makes it efficiently and safely to store electrical energy in the energy storage battery so as to provide power supply at any time[7].

\footnotetext{
${ }^{a}$ Corresponding author: zmf323@163.com
} 


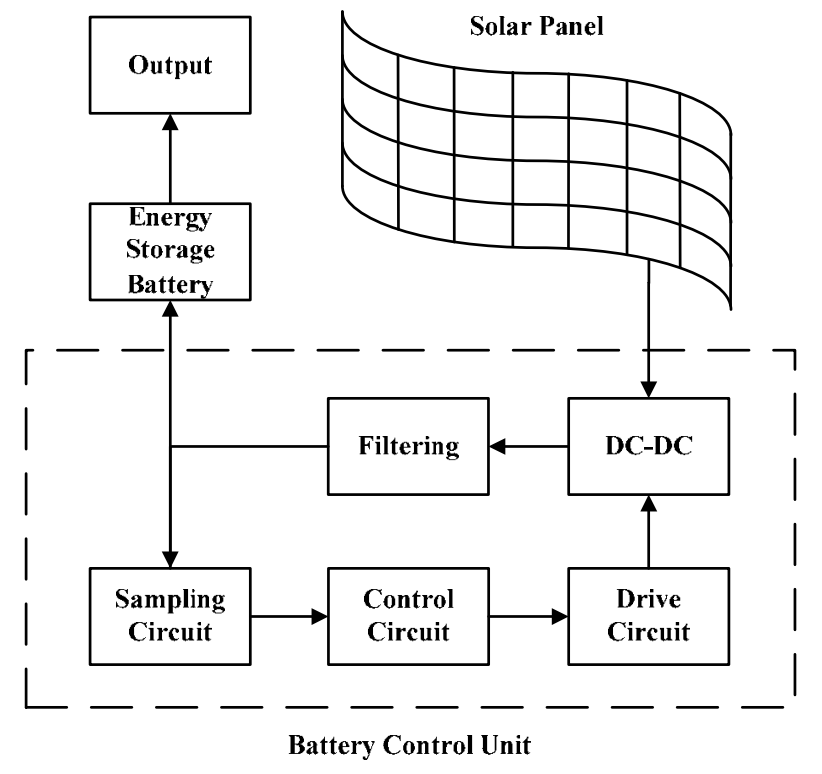

Figure 1. Overall frame of the emergency power

\section{Hardware design}

\subsection{Solar panel}

According to the photovoltaic effect, in the emergency power solar panel is the most critical part that directly converts solar energy into electrical energy.

\subsubsection{Working principle of solar panel}

The monomer of solar panel is actually a PN junction which in light produces electromotive force, namely "photovoltaic effect". The working principle of converting solar energy into electrical energy of solar panel mainly includes three processes as following:

(1) While the solar panel absorbs photons, electron-hole pairs, namely photo-induced carriers, appear in PN junction. The electrons are negatively charged and the holes are positively charged;

(2) The photo-induced carriers with opposite polarity are separated in the electrostatic field produced by PN junction;

(3) If electrodes and lead wires are led out from both sides of PN junction and are connected with loads, in the effect of internal electric field, the electrons and holes of the photo-induced carriers are separately absorbed by positive electrode and negative electrode of the solar panel, which produces electrical current in the load circuit. Sequentially electric power is output and electric energy is gained.
The working principle of solar panel is shown in Figure 2.

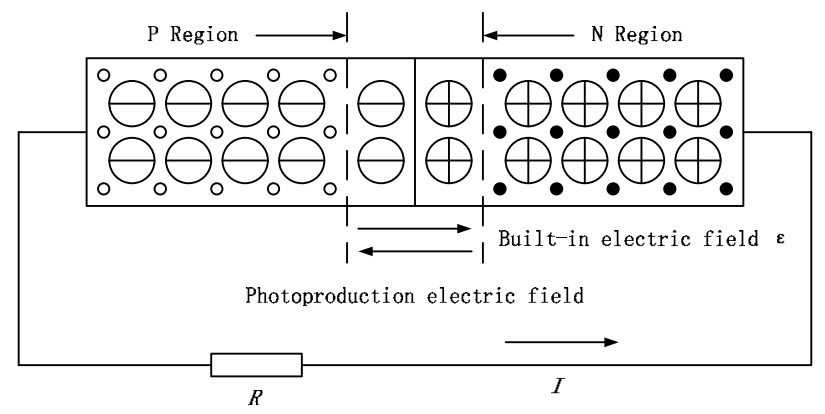

Figure 2. Working principle of solar panel

\subsubsection{Equivalent circuit of solar panel}

Figure 3 shows the equivalent circuit of solar panel. When sun light intensity is constant, the solar panel produce electric current called as $\mathrm{I}_{\mathrm{ph}}$, which doesn't change with the working status of solar panel, so the solar panel is equal to constant current source $[8,9]$. The ends of the solar panel connect a diode and a bleeder resistance $\left(\mathrm{R}_{\mathrm{sh}}\right)$ in parallel, and connect a load $\left(\mathrm{R}_{\mathrm{L}}\right)$ with a series resistance $\left(R_{s}\right)$. $R_{s}$ mainly contains resistance of the panel itself, surface resistance and contact resistance of electrode connection materials. $R_{s h}$ is a bleeder resistance that was caused by potential tiny cracks of the solar panel's edges and metal electrodes during the course of panel fabrication, which is the defects of silicon itself. $R_{s}$ and $R_{s h}$ are both self-resistances of solar panel and can be neglected in ideal model calculation. $R_{S}$ is generally small, and the bigger resistance, the greater line loss, the lower efficiency of the solar panel. The value of $R_{s h}$ is in thousands of the above[10, 11].

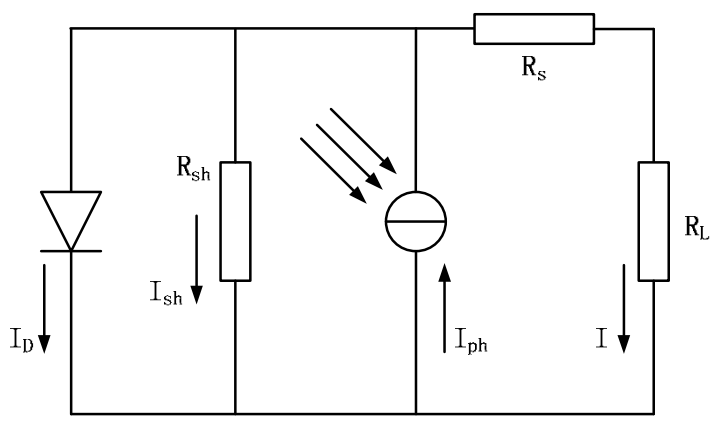

Figure 3. Equivalent circuit of solar panel 


\subsubsection{Selection of solar panel}

Choosing energy storage battery with $12 \mathrm{~V} / 24 \mathrm{Ah}$ for guaranteeing continuous power supply of DC $12 \mathrm{~V}$ was feasible. It was essential for the solar panel to determine the total capacity and amount of solar cell panels in series or in parallel according to the voltage, power and lighting, etc. In order to charge up energy storage battery, also considering factors such as high charging efficiency, not too large volume and easy carrying, it was necessary to choose several silicon solar cell panels with output of $18 \mathrm{~V} / 10 \mathrm{~W}$ and size of $360 \times 120 \mathrm{~mm}$, all of which were in parallel for increasing charging current and uprating power.

\subsection{Battery control unit}

Battery control unit is the main control module of the emergency power, and the controller technology plays an important role in solar system.

\subsubsection{Selection of Microprogrammed Control Unit $(\mathrm{MCU})$}

The system requires high demand of the speed of processor and built-in module. So ARM (Advanced RISC Machine) 7 or 8-bit MCU could be chosen. Although with fast processing speed, ARM owns a high price and many of its internal resources are useless and seriously wasted when it is applied to solar charging system. Given this, 8-bit MCU is a better choice. AVR series, C8051F series, and STC12 series are all common 8-bit MCUs. Their processing speeds all can be up to 1MIPS/MHz, but C8051F series and AVR series should not be used by considering utilization ratio of internal resources and clock frequency. Therefore it was better to adopt STC12C5412AD from STC12 series as main control chip, of which the instruction code is fully compatible with traditional 8051 series and the clock frequency can be up to $48 \mathrm{MHz}$. There are abundant I/O interfaces and strong encryption function that could preferably protect the control system[12,13].

\subsubsection{Function design of battery control unit}

Battery control unit includes voltage/current acquisition unit, battery temperature collector, LCD, alarm module, power module, and serial communication module. The function block diagram is shown as Figure 4.

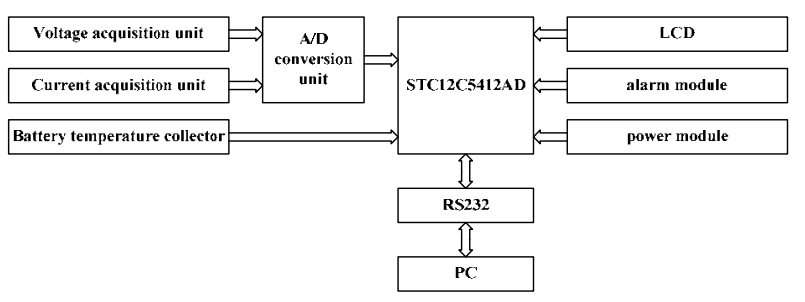

Figure 4. Function block diagram of battery control unit

Voltage acquisition unit identifies the strength of illumination and get the terminal voltage of energy storage battery. Current acquisition unit is used for over-current protection and load power detection. Battery temperature collector is used for energy storage battery's temperature compensation[14]. LCD is used to display voltage, current and load condition. Alarm module gives alarm signal if solar panel and energy storage battery are connected reversely, or energy storage battery is over-charging or over-discharging. Power module provides appropriate power supply for MCU and other components. Serial communication module plays a role of MCU in downloading programs, uploading system operation parameters and realizing remote control.

\subsubsection{Signal acquisition circuit}

Signal acquisition circuit is an important part of battery control unit. The protection of circuit is realized by means of that voltage acquisition unit monitors and measures terminal voltage, and current acquisition unit load current in real time, and then acquired signals are passed to main control chip through $\mathrm{A} / \mathrm{D}$ conversion unit to calculate and process. When the acquisition of the battery voltage is too low, the power supply circuit is shut down and the power supply is stopped to prevent over-discharging. And when the voltage is too high, the charge circuit is shut down to prevent over-charging. If the current is too large, the power supply circuit is cut off to protect the critical load. Take a method of partial pressure of precise resistance (error is less than 1\%) to regulate the signals measured by voltage acquisition circuit so as to make voltage reach the range the ADC port can accept[15]. Current acquisition circuit adopts a relatively safe and cost-effective scheme of low voltage 
resistance detection. Add an operational amplifier in circuit to magnify voltage into an ideal ADC inputting range, which helps to improve the precision of measurement and improve control performance. Figure 5 shows the signal acquisition circuit.
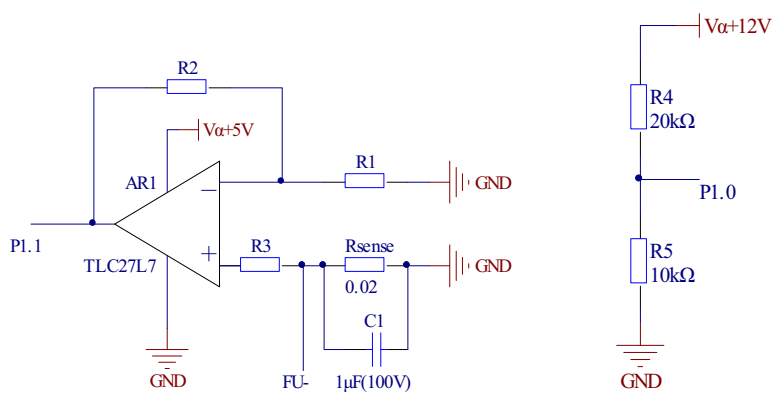

(a) Current acquisition circuit

(b) Voltage acquisition circuit

Figure 5. Signal acquisition circuit

\subsection{Energy storage battery}

For the sake of suitable and longer power supply, it is better to choose batteries, single $2 \mathrm{~V}$, and combine them into 2 pieces of energy storage batteries with $12 \mathrm{~V} / 12 \mathrm{Ah}$ in parallel. In the design of charging, the chief charging circuit based on series type of PMW reduces voltage loss of the charge circuit by nearly half compared with using diodes, which could leave energy storage battery more sufficient response time, reduce gas evolution and improve charge efficiency. Compared to the parallel controller, it is more efficient in using solar energy and reducing calorific value. Pulse charging is a cyclic method that charging with pulse current and stopping charging for a while carries out alternately. Charging impulse makes a full charge. Interval eliminates concentration polarization and ohm polarization naturally so as to reduce the internal pressure of energy storage battery, which will make the next round of constant current charge smoother. The charging circuit is shown in Figure 6.

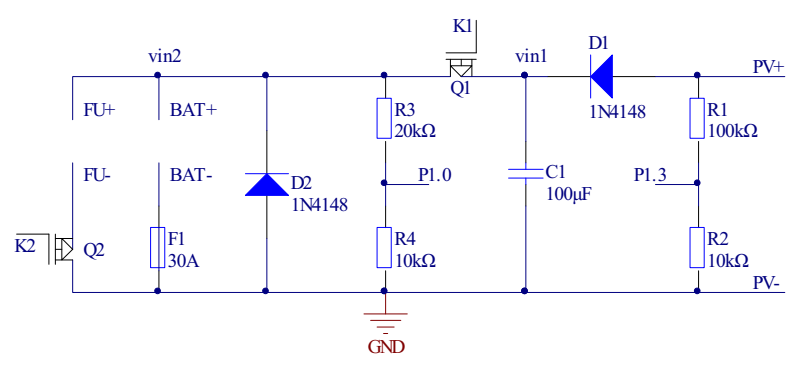

Figure 6. Charging circuit of the energy storage battery
$\mathrm{PV}+$ and PV- connect the output of the solar panel to charge the battery. FU+ and FU- link electric equipment to power the load. BAT + and BAT- connect both ends of the energy storage battery.

D1 is a backflow protection diode. D2 is a reverse polarity protection diode. If the battery polarities are reversed, battery would be short-circuit by the breakover of D2 and produce a great current to fuse the fuse protector $(\mathrm{F} 1)$, which plays a role in reverse polarity protection. MOSFET Q1 is in series in the charging circuit. When the rechargeable voltage has achieved the average charge voltage, Q1 would get the state of PWM charging to prevent over-charging. MOSFET Q2 is the discharge switch of battery. When the terminal voltage is less than over-discharging voltage during battery discharging, Q2 cut off the circuit of battery and load to avoid empty battery and damaging battery, which is over-discharging protection. When solar panel reapplies power and end voltage ascends to float charging voltage, load circuit is reconnected by Q2.

Figure 7 shows the power supply circuit. The chip $78 \mathrm{~L} 05$ can change the voltage from $12 \mathrm{~V}$ to $5 \mathrm{~V}$ for USB port. Capacitors are used to filter to make the power stable.

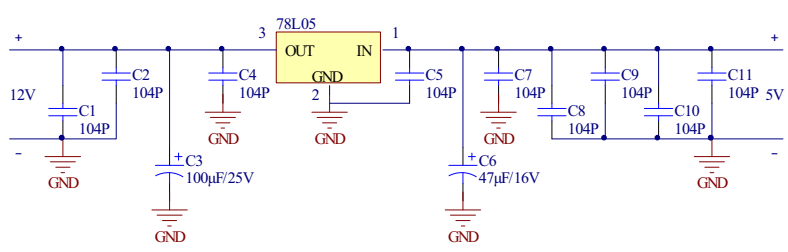

Figure 7. Schematic diagram of power supply circuit

\section{Software design}

The software design of the emergency power is as following: Real-time monitoring and protection of charging and power supply are carried out by that voltage/current acquisition unit monitors and measures the terminal voltage/load current of the battery in real time and main control chip processes the data gotten through A/D sampling port later. If the battery voltage collected is lower than $11.9 \mathrm{~V}$, the power supply circuit is shut down and the power supply is fast charged; if equal to $13.7 \mathrm{~V}$, PMW charging stage is entered; if higher than $14.4 \mathrm{~V}$, the charging circuit is shut down to avoid overcharge. 
According to the requirements of the design, the software flow pattern is shown in Figure 8.

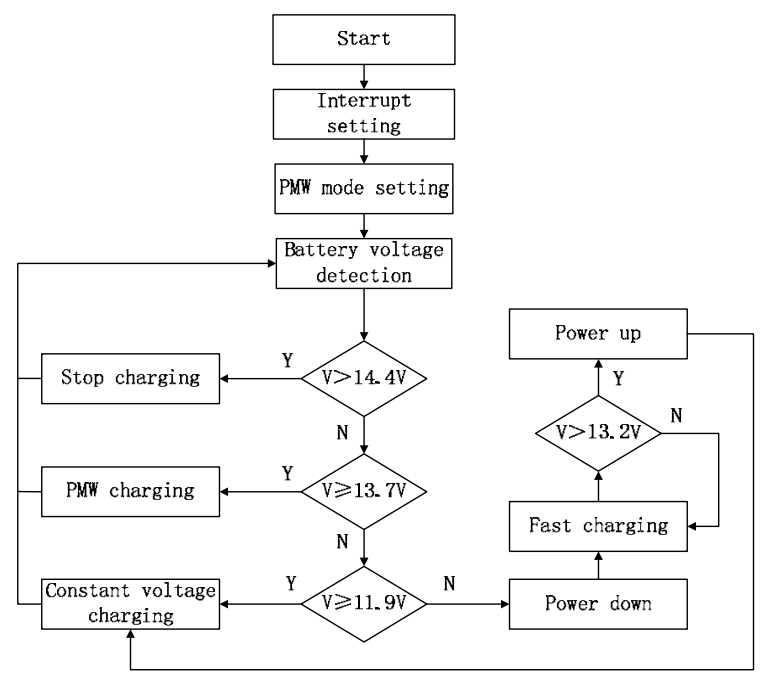

Figure 8. Software flow pattern

\section{Conclusion}

This paper adopts monocrystalline silicon solar panel in parallel as charging power supply, and takes advantage of the electric-generation principle of solar panel. Through conversion circuit and filter circuit, electrical energy converted from solar energy is stored in the energy storage battery. The emergency power realizes the safety of charging process through over-charging, over-discharging and over-current protection control. It can also provide a safe, effective and auxiliary $12 \mathrm{~V} \mathrm{AC}$ power for emergency equipment such as miniature PSA oxygen concentrator, and 5V USB power for electronic equipment. For example, mobile phone, GPS device, rechargeable light and so on. The emergency could add field service time of equipment effectively and improve people's quality of life or survival.

\section{Acknowledgements}

This work was supported by the army project (CWS12J109).

\section{References}

1. W.N. Liang, S.Y. Wang, J.Z. Tian. Emergency Medical Response. Beijing: People's Medical Publishing House (2012).

2. T. Li, G.D. Chen, G. Sun. Emergency Rescue Handbook. Beijing: Military Medical Science Press (2010).

3. P. Chen, M.F. Zhu, J. Yu, C. Deng, L. Zhu, H.B. Su,
Y.H. Yuan. Development of Portable Oxygen Concentrator. Chinese Medical Equipment Journal, 34(10), 77-79 (2013).

4. Z.M. Liu, M.F. Zhu, P. Chen, C. Deng, Y.H. Yuan, H.B. Su. Design of intelligent battery management system for miniature PSA oxygen concentrator. Electronic Design Engineering, 22, 63-65,68 (2014).

5. F. Gao, C.Q. Sun, Q.G. Liu. The Status and trends of solar energy utilization. World Sci-tech R \& D, 4, 35-39 (2001).

6. R.Q. Cui, C. Wang. Basic principle of solar cell testing system. Solar \& Renewable Energy Sources, 3, 36-40 (2008).

7. E. Trishan, L. Patrick. Chapman. Comparison of Photovoltaic Array Maximum Power Point Tracking Techniques. IEEE Transactions on Energy Conversion, 22(2), 439-449 (2007).

8. J. Chatzakis, K. Kalaitzakis, N. C. Voulgaris, S. N. Manias. Designing a new generalized battery management system. Industrial Electronics IEEE Transactions on, 50(5), 990-999 (2003).

9. P. Zhang, X.J. Wang, S.L. Wang. Design of miniwatt intelligent solar controller. Modern Electronics Technique, 18, 177-180 (2007).

10. T. Kawamura, K. Harada, Y. Ishihara, T. Todaka, T. Oshiro, H. Nakamura, M. Imataki. Analysis of MPPT characteristics in photovoltaic power system. Solar Energy Materials \& Solar Cells, 47(s 1-4), 155-165 (1997).

11. A. Zahedi, Smieee. Development of an electrical model for a PV/battery system for performance prediction. Renewable Energy, 15(s 1-4), 531-534 (1998).

12. T.X. Guo. New concept $C$ language tutorial of 51 singlechip: introduction, improvement, development and expansion. Beijing: Publishing House of Electronics Industry (2009).

13. Y.G. Zhang. New MCS - 51 single chip microcomputer application design. Harbin: Harbin Institute of Technology Press (2003).

14. S. Rodrigues, N. Munichandraiah, A. K. Shukla. Review of state-of-charge indication of batteries by means of a.c. impedance measurements. Journal of Power Sources, 87(1-2), 12-20 (2000). 
15. E. Phillip. Pascoe, H. Adnan. Anbuky. A VRLA battery simulation model. Energy Conversion \& Management, 45(s 7-8), 1015-1041 (2004). 